\title{
SFERA AUTONOMII, SFERA BIUROKRACJI. RELACJE POLSKICH TEATRÓW PUBLICZNYCH I ICH ORGANIZATORÓW W PERSPEKTYWIE MIĘDZYNARODOWEJ
}

\author{
Abstract \\ THE SPHERE OF AUTONOMY, THE SPHERE OF BUREAUCRACY. \\ THE RELATIONS OF POLISH PUBLIC THEATERS AND THEIR ORGANIZERS \\ IN AN INTERNATIONAL PERSPECTIVE
}

According to many researchers, the cultural policy model based on the arm's length principle gives public institutions more autonomy than the so-called bureaucratic model. In line with the typology by Hillman-Chartrand and McCaughey (1989), the former is called the "patron model" and implemented in the Anglo-Saxon countries. The latter, dubbed the "architect model," prevails in continental Europe, including Poland. The aim of this paper is to question the popular belief that the continental model, by definition, has a greater bureaucratic and political influence than the AngloSaxon model. For this purpose, the author has analyzed the literature describing the British practice and conducted empirical research in Poland among officials responsible for theaters and directors of public theaters. The results suggest that the difference between the two models in terms of institutional autonomy is not as clear as one could infer from the typology contained in the literature.

SŁOWA KLUCZE: polityka kulturalna, zasada przedłużonego ramienia, instytucja kultury, rada sztuki

KEY WORDS: cultural policy, arm's length princile, culture institution, art council

\section{Wstęp}

Z pojęciem „,autonomii” jest jak z pojęciami „wolności” czy „demokracji” choć używają ich wszyscy, nie ma zgody co do wspólnej definicji. Znaczenia tych słów mogą być skrajnie różne, choć skrajności tych nie dzieli przepaść, ale ledwie 
widoczne przesunięcie akcentów. Autonomia instytucji kultury może oznaczać wolność od państwa, wolność od rynku albo od Millowskiej „tyranii większości”. To ostatnie ujęcie sprawia nam kłopot, bo okazuje się, że autonomia niekoniecznie idzie w parze z demokracją. Jak twierdzi Robert Blomgren ${ }^{1}$, godzenie przez państwo woli większości z wolnością twórczą jednostek musi opierać się na paradoksie. Mimo to autonomia sztuki jest jedną z podstawowych wartości zarówno dla twórców, jak i współczesnych systemów demokratycznych. Zakłada się, że ingerencja władzy w autonomię instytucji artystycznej jest niedopuszczalna, chociaż granice autonomii są i zawsze będą czymś niedookreślonym, przedmiotem wiecznej kontestacji.

Celem tego tekstu jest analiza różnych modeli polityki kulturalnej pod kątem autonomii instytucji. Artykuł kwestionuje popularną wśród badaczy tezę, że systemy oparte na tzw. zasadzie przedłużonego ramienia (inaczej anglosaskie lub eksperckie) gwarantują instytucjom artystycznym więcej autonomii niż systemy ministerialne (biurokratyczne). Tekst podzielony jest na cztery części. W pierwszej omówiono klasyfikację modeli polityki kulturalnej Harry'ego Hillmana-Chartranda i Claire McCaughey (1989). Druga i trzecia poświęcone są dwóm modelom z tej klasyfikacji - Patrona i Architekta - oraz ich wpływowi na autonomię sztuki. Do analizy pierwszego z nich zostały użyte przykłady brytyjskie, do omówienia drugiego - badania przeprowadzone w Polsce. Część ostatnia zawiera podsumowanie i wnioski.

\section{Patron i Architekt - dwa modele polityki kulturalnej}

W roku 1989 kanadyjscy ekonomiści kultury - Harry Hillman-Chartrand i Claire $\mathrm{McCaughey}^{2}$ stworzyli klasyfikację, która weszła na stałe do obiegu akademickiego i stała się punktem wyjścia analiz interwencjonizmu państwa w kulturze. Badacze wyodrębnili cztery typy (,modele”) publicznego mecenatu: Pomocnik (ang. facilitator), Patron (ang. patron), Achitekt (ang. architect) oraz Inżynier (ang. engineer). Typ pierwszy polega na wspieraniu kultury przez wprowadzanie ulg i zwolnień podatkowych - zarówno dla twórców (np. zwolnienia z podatku dochodowego i VAT), jak i filantropów. W ten sposób decyzja o kierunku dystrybucji środków na kulturę powierzana jest obywatelom, którym „opłaca się” samodzielne wspieranie sztuki. Typ drugi (Patron) zakłada dystrybucję środków przez rady sztuki funkcjonujące w stosunku do władz publicznych na „odległość ramienia” (ang. arm's length). Rada sztuki, w której zasiadają niezależni eksperci, podejmuje decyzje o przyznaniu grantów dla instytucji artystycznych. Model Architekta opiera się na działalności krajowych ministerstw kultury oraz ich regionalnych i lokalnych odpowiedników. W tym wypadku to urzędnicy i politycy podejmują decyzję o podziale środków publicznych.

${ }^{1}$ R. Blomgren, Autonomy or democratic cultural policy: that is the question, „International Journal of Cultural Policy" 2012, nr 18 (5), s. 519-529.

${ }^{2} \mathrm{H}$. Hillman-Chartrand, C. McCaughey, The arm's length principle and the arts: an international perspective - past, present and future [w:] M. Cummings, J.M.D. Schuster (red.), Who's to pay for the arts? The international search for models of support, New York 1989. 
W modelu Inżyniera działalność artystyczna jest podporządkowana celom politycznym - mowa tu o systemach autorytarnych lub totalitarnych.

Jak każda typologia, i ta oparta jest na uproszczeniach. Chociaż teoretyczne schematy pozwalają radzić sobie ze złożonością materii, nie oddają sprawiedliwości życiu, czyli temu, co konkretne i jednostkowe. Należy zastrzec, że nie istnieją „,czyste” realizacje opisanych modeli. Chociaż model oparty na zasadzie arm's length (Patrona) i model biurokratyczny (Architekta) wydają się najbardziej reprezentatywne dla europejskich systemów wspierania kultury, zaś model fiskalny (Pomocnika) jest najbliższy polityce kulturalnej USA, zachęty podatkowe są w Europie nie tylko powszechnie stosowane, ale zaczynają mieć w finansowaniu kultury coraz większe znaczenie ${ }^{3}$.

Modele nie tyle więc reprezentują kompletne systemy zarządzania kulturą, ile dominujące zasady, które tymi systemami rządzą. Model Patrona utożsamiany jest $\mathrm{z}$ tzw. zasadą przedłużonego ramienia (ang. arm’s length principle), która zakłada, że dystrybucja środków na kulturę musi być niezależna od partyjnych ideologii oraz partykularnych interesów rządzących. W radach sztuki (Arts Council) zasiadają niezależni eksperci: artyści, krytycy, akademicy, którzy podejmują decyzje w trybie recenzenckim. System ocen eksperckich niesie ryzyko faworyzowania projektów ambitnych artystycznie, a przy tym zaniedbywania potrzeb społeczności gorzej wykształconej, o niższych kompetencjach kulturowych.

Inną zasadą rządzi się model Architekta. Tu fundamentem jest legitymizacja, którą cieszy się władza wyłoniona w procesie demokratycznych wyborów. O finansowaniu przedsięwzięć artystycznych decydują urzędnicy i politycy, ponoszący odpowiedzialność za środki publiczne. Zaletą tego modelu jest redystrybucja środków nastawiona na zaspokojenie potrzeb kulturalnych jak największej liczby obywateli. Zakłada się, że politycy - chcąc pozyskać przychylność wyborców - nie będą zaniedbywać żadnej grupy społecznej. Wadą modelu jest upolityczniony system finansowania kultury.

Obie koncepcje mają mocne i słabe strony, ale z punktu widzenia autonomii instytucji i artystów to model ekspercki jest na ogół uznawany za lepsze rozwiązanie ${ }^{4}$. Wśród badaczy polityki kulturalnej istnieje dość powszechna zgoda, że zasada przedłużonego ramienia zapewnia więcej swobody twórczej niż system ministerialny (biurokratyczny), niosący ze sobą ryzyko politycznej cenzury ${ }^{5}$. Analiza literatury zagranicznej pozwala stwierdzić, że rady sztuki uważane są za rodzaj bufora chroniącego przed niechcianą interwencją władz publicznych. Według Rogera Blomgre$\mathrm{na}^{6}$, w dyskursie polityki kulturalnej pojęcia „autonomia” i „zasada przedłużonego

${ }^{3}$ Department for Culture, Media and Sport, Charitable Giving Indicators Publication 2014/2015, 2015, https://www.gov.uk/government/statistics/charitable-giving-indicators-201415 [odczyt: 15.02.2017].

${ }^{4}$ Por. F. van der Ploeg, The Making of Cultural Policy: a European Perspective, Working Paper no. 1524, Monachium 2005.

${ }^{5} \mathrm{C}$. Madden, The independence of government arts funding: a review, „D'Art Topics in art Policy" 2009, nr 9; P. Mangset, The arm's length principle and the art funding system: comparative approach [w:] M. Pyykkönen, N. Simanainen and S. Sokka (red.), What about cultural policy? Interdisciplinary perspectives on culture and politics, Jyväskylä 2009, s. 273-298.

${ }^{6}$ R. Blomgren, dz. cyt., s. 519. 
ramienia" są zwykle tożsame. Anne Rosser Upchurch ${ }^{7}$ zauważa, że dystans między rządem a instytucjami i procesami twórczości artystycznej od początku był podstawą brytyjskiego systemu finansowania sztuki, skonceptualizowanego i wprowadzonego w życie po II wojnie światowej przez Johna Maynarda Keynesa. Stephen Hetherington ${ }^{8}$, odwrotnie niż Upchurch, widzi w zasadzie arm's length nie tyle emblemat powojennego welfare state, ile wyraz poparcia dla wolności indywidualnej i filozofii politycznej laissez-faire. Ta różnica zdań nie ma tu jednak większego znaczenia, bo obie teorie głoszą supremację wolności osobistej jednostki, a w dziedzinie twórczości artystycznej - autonomię i niezależność od partyjnego dyktatu. Obie widzą w zasadzie arm's length szansę realizacji tych ideałów.

\section{Autonomia instytucji artystycznej w modelu Patrona}

Wśród badaczy polityki kulturalnej powyższe poglądy wydają się dominujące. Nie sposób jednak oprzeć się wrażeniu, że bazują one raczej na apoteozie założeń systemu arm 's length niż obserwacji i praktyce. W takiej sytuacji trudno przecenić prace pozwalające zajrzeć w głąb relacji między ekspertami, władzą publiczną a instytucjami artystycznymi - autorstwa m.in. Ruth-Blandiny M. Quinn i Eleonory Belfiore. Prace te dostarczają argumentów, które można ułożyć w trzy główne wątki:

Po pierwsze, mimo forsowania przez władze publiczne tezy, że ciała eksperckie są od nich niezależne, w praktyce zależności między jednymi a drugimi są większe, niż chcielibyśmy sądzić. Według Quinn" ${ }^{9}$ związki między rządem i Radą Sztuki w Wielkiej Brytanii od zawsze (tj. od czasu powstania Rady w 1946 roku) charakteryzowała raczej zażyłość niż dystans. Wynikało to zarówno z warunków formalnych, jak i nieformalnych, np. relacji międzyludzkich, osobistych motywacji oraz kultury politycznej. Formalne uzależnienie związane było z uprawnieniami rządu do powoływania członków Rady (zarówno komisji eksperckiej, jak i zaplecza administracyjnego), ustalania wysokości jej budżetu, okresowego rozliczania i kontroli. A jednak to nie zasady explicite wyartykułowane w Karcie królewskiej ${ }^{10}$, ale stosunki i praktyki nieformalne miały decydujące znaczenie dla relacji między Radą o rządem. Sporego pola do manewru dostarczała nieprecyzyjność przepisów (np. kto może zasiadać w Radzie albo jakie dziedziny sztuki powinny być finansowane), która w założeniu miała przenosić decyzyjność na Radę Sztuki, ale w rzeczywistości tworzyła warunki

7 A.R. Upchurch, Keynes's legacy: an intellectual's influence reflected in arts policy, „International Journal of Cultural Policy" 2011, nr 17 (1), s. 69-80.

${ }^{8} \mathrm{~S}$. Hetherington, Arm 's-length funding of the arts as an expression of laissez-faire, „International Journal of Cultural Policy" 2015, nr 23 (4) s. 482-494.

${ }^{9}$ R.-B. M. Quinn, Distance or intimacy? The arm's length principle, the British government and the arts council of Great Britain, ,International Journal of Cultural Policy” 1997, nr 4 (1), s. 127-159.

${ }^{10}$ Karta królewska (Royal Charter) to akt prawny, który wydaje monarcha. Za jego pomocą od czasów średniowiecza nadawano prawa miejskie, tworzono uniwersytety. Obecnie Karty królewskie regulują działalność m.in. BBC, British Council czy Arts Council England. 
do obsadzania stanowisk po linii partyjnej. W rezultacie Rada była często lustrzanym odbiciem aktualnego składu rządu, powielając „zarówno jego poglądy, jak i klasę"11. Mimo zmian w polityce i odmiennych, wydawałoby się, poglądów co do zadań państwa w kulturze, kolejne Karty królewskie (z roku 1967, 1985 i 1994) w zasadzie legitymizowały status quo. Nawet Partia Konserwatywna (od 1979 roku), której celem była decentralizacja i dywersyfikacja finansowania kultury (m.in. przez uruchomienie licznych inicjatyw w zakresie sponsoringu sztuki), dążyła do centralizacji i podporządkowania Rady nowo powstałemu Departamentowi Dziedzictwa Narodowe$\mathrm{go}^{12}$. Według Quinn, od roku 1946 do lat dziewięćdziesiątych XX wieku zasada arm 's length nie tyle oznaczała autonomię, ile była „tarczą” i „maską” zarówno dla rządu, jak i ekspertów. Tarczą - bo zwalniała rząd z odpowiedzialności za finansowanie potencjalnie kontrowersyjnych projektów oraz usprawiedliwiała niejawny i nietransparentny system decyzyjny komisji eksperckich tym, że jedynym kryterium oceny miał być ich subiektywny gust. Maską - bo przysłaniała interwencję rządu i czyniła ją niejawną. Jak pisze David Jones ${ }^{13}$, w Wielkiej Brytanii protesty polityków przeciw decyzjom Rady Sztuki zdarzają się sporadycznie. Nic dziwnego - są to na ogół ich własne decyzje.

Po drugie, systemy eksperckie są bardziej zorientowane na wyniki instytucji artystycznych, przez co mogą mieć bardziej „opresyjny” charakter niż systemy biurokratyczne. Z międzynarodowej analizy porównawczej ${ }^{14}$ wynika, że kontynentalno-europejski styl administrowania, choć wysoce biurokratyczny, daje szeroki zakres władzy dyrektorom artystycznym. W przeciwieństwie do Francji czy Hiszpanii, gdzie umowy o finansowaniu między instytucją a jej organizatorem przypominają ogólny plan działań bez konkretnych celów czy kryteriów rozliczania organizacji, brytyjskie kontrakty (performance contracts), zawierane co trzy lata między instytucjami artystycznymi a Radą Sztuki ${ }^{15}$, opierają się na szczegółowych wskaźnikach oceny. Tendencja do kontraktowych metod organizowania działalności kulturalnej nasiliła się w późnych latach dziewięćdziesiątych XX wieku, gdy władzę objęła Nowa Partia Pracy (New Labour). Ugrupowanie, pod przywództwem najpierw Tony’ego Blaira, a później Gordona Browna, realizowało politykę zwaną Trzecią Drogą, mającą łączyć zalety socjalizmu i kapitalizmu oraz opierać procesy decyzyjne na dowodach i wiedzy eksperckiej raczej, niż uznaniowych sądach rządzących. Rozpoczął się proces „depolityzacji”"16

11 R.-B. M. Quinn, dz. cyt., s. 130.

12 Skromniejsza, brytyjska wersja ministerstwa kultury, w 1997 r. przemianowana na Departament Kultury, Mediów i Sportu (DCMS).

${ }_{13}$ R.-B. M. Quinn, dz. cyt., s. 131.

14 J.R. Ulldemolins, A.R. Arostegui, The governance of national cultural organisations: comparative study of performance contracts with the main cultural organisations in England, France and Catalonia (Spain), „International Journal of Cultural Policy” 2013, nr 19 (2), s. 249-269.

${ }^{15}$ W Wielkiej Brytanii organizacje artystyczne, a więc te z obszaru sztuk scenicznych (np. teatry, opery, zespoły taneczne, orkiestry, ale i niektóre centra sztuki), są finansowane przez Radę Sztuki. Instytucje związane z dziedzictwem (np. National Gallery, British Museum) podlegają zaś rządowemu Departamentowi Kultury, Mediów i Sportu.

${ }^{16}$ P. Burnham, New Labour and the politics of depoliticisation, „British Journal of Politics and International Relations" 2001, nr 3 (2), s. 127-149. 
sfery publicznej. Centralne i lokalne urzędy położyły nacisk na kontrolę i ewaluację, której wynikiem była „eksplozja audytów” ${ }^{17}$. Eleonora Belfiore podkreśla, że źródłem presji wywieranej na instytucje artystyczne był nie tylko Departament Kultury, Mediów i Sportu (brytyjski odpowiednik ministerstwa kultury), ale również Rada Sztuki, która razem z władzą centralną wypracowywała technokratyczne metody ewaluacji. Po raz kolejny okazało się, że organizacja mająca funkcjonować „na odległość ramienia” od rządu, działa z nim „ramię w ramię”. Co istotne, instytucje były oceniane już nie tylko za realizację programu artystycznego, ale za to, jak bardzo przyczyniają się do innych, szerzej pomyślanych celów polityki państwa, np. wzrostu gospodarczego, rozwoju społecznego, edukacji czy przeciwdziałania przestępczości. Polityka kulturalna laburzystów zakładała, że sztuka warta subsydiowania to ta, która się „liczy” w znacznie szerszej, nie tylko artystycznej perspektywie. Instytucje musiały przekierować część uwagi i zasobów z działalności artystycznej na działalność związaną z kolekcjonowaniem danych i „twardych” dowodów na zasadność własnego istnienia.

Po trzecie, finansowanie oparte na sądach eksperckich nie oznacza wbrew pozorom pełnej wolności twórczej. Zdaniem Christophera Maddena ${ }^{18}$, w systemie arm's length panel ekspercki może być po prostu substytutem urzędników, a cenzura środowiskowa zastępować cenzurę polityczną. Chociaż eksperci są na pewno bardziej „kompetentni” i lepiej „technicznie” przygotowani, ich oceny nie są mniej uznaniowe, ani też wolne od koterii i towarzyskich układów. Milton C. Cummings i Richard S. Katz piszą:

Eksperymentator czy ikonoklasta może czuć się lepiej przed komisją biurokratów niż panelem złożonym z artystów i dyrektorów instytucji kultury. Decyzje podejmowane przez samoreprodukujące się towarzystwa nie muszą być wcale mniej arbitralne czy potencjalnie krzywdzące, zwłaszcza jeśli w ich skład wchodzą wzajemnie wspierający się przedstawiciele tych samych kręgów artystycznych ${ }^{19}$.

Nie ma to oznaczać, że członkowie ciał eksperckich są źle usposobieni czy nieprofesjonalni. Problem jest innej natury - jak piszą James G. March i Johan P. Olsen ${ }^{20}$ :

[...] specjaliści, podobnie jak inni ludzie, dostrzegają fakty i teoretyczne implikacje zgodne $\mathrm{z}$ ich preferencjami politycznymi, a zapominają o faktach i teoretycznych implikacjach niewygodnych z punktu widzenia ich celów. Specjalistyczne opinie nie są w czarodziejski sposób chronione przez osobistym zaangażowaniem i profesjonalną tendencyjnością.

Nie jest to głos na rzecz dyskredytacji specjalistów, ale zachowania ostrożnego stosunku do eksperckich roszczeń, do obiektywności i naukowości.

${ }^{17}$ E. Belfiore, Auditing culture: the subsidised cultural sector in the New Public Management, „International Journal of Cultural Policy” 2004, nr 10 (2), s. 183-202.

${ }^{18}$ C. Madden, dz. cyt., s. 23.

${ }_{19}$ M. Cummings, R. Katz, Government and the arts: an overview [w:] M. Cummings and R. Katz (red.), The patron state: government and the arts in Europe, North America and Japan, New York-Oxford 1987, s. 16.

${ }^{20}$ J.G. March, J.P. Olsen, Instytucje. Organizacyjne podstawy polityki, Warszawa 2005, s. 42. 


\section{Autonomia instytucji artystycznej w modelu Architekta}

Biurokratyczne systemy zarządzania kulturą uchodzą za bardziej upolitycznione, a więc bardziej podatne na wpływy ideowo-polityczne, niż systemy eksperckie. Te pierwsze są zwykle przypisywane krajom Europy kontynentalnej, te drugie - Wielkiej Brytanii. Chociaż podział ten jest już od dawna nieaktualny (np. w Holandii, Skandynawii czy krajach bałtyckich rady sztuki są powszechnym rozwiązaniem), nadal obowiązuje on w zbiorowej wyobraźni badaczy, głównie w wyniku uznania zasady przedłużonego ramienia za „tradycyjnie brytyjski” wynalazek, który inne kraje „pożyczają” i adaptują na swój użytek. Znaczący jest tu również fakt, że Francja i Niemcy nigdy nie stworzyły u siebie eksperckich agencji do spraw sztuki - mimo swoistych wad rodzimych systemów, nie odczuwano w tych krajach potrzeby adaptowania brytyjskich rozwiązań ${ }^{21}$. W Europie Środkowo-Wschodniej podejście do rad sztuki jest znacznie mniej jednoznaczne. Jak zauważa węgierski badacz Peter Inkei ${ }^{22}$, w naszym regionie tradycje administracji publicznej ścierają się z popularnością kultury anglosaskiej i przekonaniem o skuteczności, a nawet bezalternatywności wpisanych w nią rozwiązań. Według Inkeiego, jedną z oczywistych, a w gruncie rzeczy banalnych przyczyn jest dostępność angielskiej literatury, dzięki której racje przemawiające za systemem arm's length są nam lepiej znane niż argumenty francuskie czy niemieckie. Inkei wspomina, jak podczas sesji dotyczącej francuskiego systemu finansowania kultury w Budapeszcie między uczestnikami węgierskimi i francuskimi nastąpił komunikacyjny impas: ci pierwsi uznawali za oczywiste, że w zachodnich demokracjach nie ma alternatywy dla niezależnych ciał eksperckich; ci drudzy - że odpowiedzialność za środki publiczne ponoszą członkowie administracji państwowej.

Należy przy tym zaznaczyć, że tak jak nie istnieją „,czyste” modele, tak systemom niemieckiemu czy francuskiemu zasada przedłużonego ramienia nie jest zupełnie obca. Francuskie ministerstwo kultury powołuje specjalistyczne rady lub komisje oraz korzysta z porad ekspertów, gdy w grę wchodzą decyzje artystyczne, np. zakup dzieł sztuki do państwowych kolekcji lub przyznawanie grantów twórcom filmowym ${ }^{23}$. Bliskość władzy publicznej i dyrektorów instytucji kultury decyduje jednak o uznaniu francuskiego systemu za silnie upolityczniony. Twierdzi tak m.in. Per Mangset, wskazując, że dyrektorzy francuskich teatrów są mocno zależni od ministrów kultury, a „każda zmiana na scenie politycznej oznacza wymianę dyrektorów instytucji” ${ }^{24}$.

${ }^{21}$ P. Inkei, Arm's Length Financing in Culture: Why? Why Not?, Budapeszt 2001, http://www. budobs.org/grant-paper-dec.htm [odczyt: 13.02.2015], oraz D. Loosely, Cultural policy in France since 1959: arm's length, or 'up close and personal?', Kopenhaga 2001.

${ }^{22}$ P. Inkei, Why Not Indeed?, Budapeszt 2002, http://www.budobs.org/grant- paper02.htm [odczyt: 3.03.2016].

${ }^{23}$ D. Looseley, dz. cyt., s. 3.

${ }^{24}$ P. Mangset, dz. cyt., s. 287. 
Problem relacji między władzami publicznymi a dyrektorami teatrów brzmi w Polsce aż nadto znajomo. Polski system zarządzania kulturą wpisuje się w model Architekta: mimo miejscowych adaptacji zasady arm's length (np. w ministerialnych programach grantowych), ciężar decyzyjności spoczywa na przedstawicielach władzy. Mimo prerogatyw administracji publicznej, badacze są skłonni uważać, że polskie instytucje posiadają autonomię finansową i merytoryczną ${ }^{25}$. Według analityków prawnych, zachowują one niezależność w prowadzeniu gospodarki finansowej, choć muszą brać pod uwagę zasadę efektywności ${ }^{26}$. Niezależność merytoryczna wynika z ograniczonego wpływu organizatora na bieżące funkcjonowanie instytucji. Organizator nakreśla ogólne ramy jej funkcjonowania przez uchwalenie statutu, powołuje dyrektora lub formułuje kryteria jego wyboru oraz definiuje zobowiązania dyrektora w kontrakcie. Może mieć zatem znaczącą rolę w momencie selekcji zarządzającego instytucją, jednak następujący potem nadzór ma charakter głównie administracyjny.

\section{a) Relacje teatrów publicznych i ich organizatorów w Polsce - badanie}

Podobny obraz wyłania się z badania ilościowo-jakościowego relacji teatrów i ich organizatorów ${ }^{27}$. Procedura badania była dwuetapowa. W etapie pierwszym (marzec-maj 2015 roku) wysłano ankietę do organizatorów teatrów w całej Polsce na poziomie miejskim, wojewódzkim i ministerialnym (łącznie 54 organizatorów, z czego odpowiedziało $37-69 \%$ ). Kwestionariusz zawierał pytania otwarte, co dawało możliwość swobodnej odpowiedzi. Pytania dotyczyły poglądów respondentów dotyczących polityki w sferze teatrów, a także instrumentów i metod prowadzenia tej polityki. Wyniki badania zaprezentowano podczas publicznej debaty w Instytucie Teatralnym (maj 2015 roku), na którą zaproszono przedstawicieli samorządów. W etapie drugim wykorzystano metodę zogniskowanej dyskusji grupowej: wyniki badania przekazano do analizy dyrektorom teatrów podczas jednego ze spotkań tzw. Grupy Roboczej ${ }^{28}$. W ten sposób uzyskano ich opinie na temat relacji z organizatorami.

Wyniki badania uporządkowane zostały według czterech wątków tematycznych:

25 J. Hausner, K. Malczyk, Ł. Maźnica, J. Strycharz, Diagnoza potencjału podmiotów kultury w zakresie realizacji Programu Rozwoju Kultury 2020: analiza sytuacji zastanej, Kraków 2016.

26 J. Hołda, Komentarz do ustawy o organizowaniu i prowadzeniu działalności kulturalnej, Warszawa 2012, oraz E. Tomczyk, Instytucja kultury nie jest formalnie podporzadkowana swojemu organizatorowi, 2012, http://www.samorzad.lex.pl/czytaj/-/artykul/instytucja-kultury-nie-jest-formalnie-podporzadkowana-swojemu-organizatorowi/ [odczyt: 13.03.2017].

27 Badanie zostało przeprowadzone przez Autorkę tekstu przy udziale członków zespołu ds. polityk teatralnych: Anny Galas (Instytut Teatralny) i Pawła Płoskiego (Akademia Teatralna im. A. Zelwerowicza w Warszawie).

${ }^{28}$ Grupa Robocza to ogólnopolski zespół funkcjonujący przy Instytucie Teatralnym, złożony $z$ dyrektorów teatrów, badaczy, krytyków i pracowników instytucji teatralnych. Cykliczne spotkania zespołu stanowią kontynuację tzw. Narady Gdańskiej, czyli plenarnego spotkania (wrzesień 2015 r.) wokół tematyki systemu teatralnego w Polsce. 


\section{Rola teatrów w polityce kulturalnej samorzq̨dów}

\section{Organizatorzy teatrów}

Respondenci wyrażali przekonanie, że polityka kulturalna w sferze teatrów to raczej sposób współpracy i kształtowania relacji z konkretnymi instytucjami, a nie dhugofalowa strategia oparta na założeniach ideowych. Pojawiały się również opinie, że nie ma czegoś takiego jak szeroko pojmowana „,polityka teatralna”, że zadaniem organizatora jest raczej ,dialog z konkretnym teatrem”, polegający w praktyce na finansowaniu placówki oraz powoływaniu jej dyrektora.

Co to znaczy ,polityka teatralna”? Działamy $w$ obszarze prawa $i$ w obszarze możliwości. Mówiac o prawie, mam na myśli ustawy określające obowiazki państwa i samorząów w kwestii organizowania $i$ prowadzenia działalności kulturalnej. Możliwości - to przede wszystkim ograniczenia finansowe.

Odpowiadając na pytanie o cele polityki kulturalnej w sferze teatrów, respondenci wymieniali ogólne zadania prospołeczne, takie jak: podnoszenie poziomu uczestnictwa w kulturze, rozwijanie kompetencji kulturowych mieszkańców, edukacja dzieci i młodzieży, kształtowanie postaw etycznych i wrażliwości estetycznej, podnoszenie rangi miasta. Dominowało podejście skupiające się na kulturotwórczej roli teatrów, rzadko pojawiały się głosy wskazujące na instrumentalne traktowanie sztuki, np. niewielu respondentów wskazało na rolę teatrów w rozwoju gospodarczym (,rozwój kompetencji kreatywnych, ważnych dla rozwoju innowacyjnej gospodarki”). Dość często pojawiał się za to wątek autonomii instytucji. Respondenci podkreślali, że działalność teatralna nie jest podporządkowana żadnym nadrzędnym „,celom”, które rozumiano jako cele ideowo-polityczne. Pytanie o cele polityki kulturalnej budziło u niektórych respondentów negatywne skojarzenia z ,minioną epoką", czyli poprzednim ustrojem politycznym, od którego organizatorzy wyraźnie się dystansowali.

Władze województwa $X$ dalekie sa od używania teatrów jako narzędzi osiagania celów politycznych, szanując tym samym wspomniana już wyżej autoteliczność sztuki, w tym twórczości teatralnej.

\section{Dyrektorzy teatrów ${ }^{29}$}

Rozmowy z dyrektorami ujawniły polaryzację opinii o udziale władz publicznych w kształtowaniu działalności teatralnej. $Z$ jednej strony, część respondentów krytycznie oceniała podejście władz które - ich zdaniem - znamionuje brak „namysłu” nad rolą teatru w regionie oraz ,wizji” co do sposobu funkcjonowania instytucji. Zdaniem dyrektorów, organizatorzy teatrów są zorientowani na przestrzeganie procedur oraz realizację zadań ściśle administracyjnych i doraźnych, które nie są oparte na długoterminowych planach lub szerszej perspektywie. Respondenci uważali, że władze powinny wykazać się bardziej „wzniosłym” spojrzeniem na finansowanie kultury. Ponadto zwracali uwagę, że obowiązkiem władz jest definiowanie kryteriów, które instytucje powinny spełniać jako realizatorzy określonej misji społecznej.

Nie ma watpliwości, że teatry powinny zachować autonomie $w$ kwestii decyzji repertuarowych $i$ innych kwestiach artystycznych. To jednak nie zwalnia władz publicznych z odpowiedzialności za definiowanie roli teatru $i$ tego, na czym polega jego użyteczność na danym terenie. Samorzad mógłby choćby rozstrzygać kwestie, czy dany teatr powinien podejmować działania edukacyjno-społeczne, czy koncentrować się na świetnych artystycznie produkcjach.

Organizator ma prawo formułować swoje oczekiwania wobec teatru po to, by zaspokajat on potrzeby mieszkańców miasta. Należy domagać się, by takie oczekiwania byly formułowane $i$ aby teatr byt oceniany również ze względu na pożyteczność dla miejsca, w którym się znajduje.

Z drugiej strony, dyrektorzy podkreślali, że ograniczanie się przez władze do rutynowej administracji zapewnia neutralność, a nawet w pewnym stopniu „obojętność” wobec instytucji. Według części respondentów nie należy tej sytuacji postrzegać negatywnie. Przeciwnie: im mniej samorządowej „wizji” kultury, tym lepiej. Taka „wizja”, zdaniem respondentów, może prowadzić do narzucania przez władze konkretnych programów dla teatru i ograniczania wolności artystycznej.

${ }^{29}$ Fragmenty wypowiedzi dyrektorów teatrów zostały zredagowane w celu lepszej czytelności tekstu. 
„Jakie cele władze pragna osiagnać” - przepraszam, ale to brzmi jak pytanie co najmniej z minionej epoki.

Samorzadowe instytucje kultury sq niezależnymi podmiotami publicznymi (w prowadzeniu wtasnej działalności i zaciaganiu zobowiazań finansowych) oraz jednocześnie samorzadowymi jednostkami organizacyjnymi. Ich działalność programowa nie jest determinowana przez władze!!!
Przestrzegałbym przed domaganiem się od władz formułowania jakichkolwiek zaleceń dla teatru. Nie po to tyle lat walczylismy przeciwko władzy PRL, by teraz domagać się powrotu politycznych „, wizji”. W końcu mamy autonomię teatru i nie rozumiem, po co mielibyśmy domagać się większego nadzoru władz nad instytucjami.

\section{Wpływ organizatora: nadzór, kontrola, ewaluacja}

\section{Organizatorzy teatrów}

Respondenci wskazywali na dwa podstawowe instrumenty kontroli i ewaluacji instytucji teatralnych. Pierwszy to umowy z dyrektorami, drugi to cykliczne sprawozdania z działalności.

Umowy z dyrektorami są z reguły standardowym dokumentem definiującym obowiązki obu stron. Podstawowym obowiązkiem organizatora jest zapewnienie teatrowi środków finansowych na rok bieżący i kolejne lata obejmujące kadencję dyrektora. Wysokość środków, w podziale na dotację celową i podmiotową, precyzuje umowa. Podstawowym obowiązkiem dyrektora jest realizacja programu (w przypadku konkursu programem jest aplikacja kandydata). Niektóre umowy zawierają wskaźniki oceny, z reguły ograniczone do tych podstawowych (liczba premier, spektakli i widzów w sezonie).

Sprawozdawczość instytucji jest ograniczona do udostępniania danych ilościowych: przychodów (i ich źródeł) oraz kosztów, liczby premier i spektakli, liczby scen i miejsc na widowni, liczby sprzedanych biletów oraz frekwencji, liczby zatrudnionych w zespołach artystycznych i administracyjnych, a także informacji na temat działalności edukacyjnej, wyjazdów zagranicznych i występów na festiwalach.

Respondenci wskazywali, że obecna forma sprawozdawczości wynika ze standaryzacji procedur, tj. wszystkie teatry raportują według tego samego schematu. Niektórzy respondenci wyrażali przekonanie, że ograniczanie ewaluacji do podstawowych danych ilościowych gwarantuje neutralność i świadczy o niechęci organizatora do oceny artystycznej teatru oraz ingerencji w kwestie programowe.

\section{Dyrektorzy teatrów}

Dyrektorzy byli zdania, że obecny system ewaluacji teatrów służy wyłącznie celom biurokratycznym, o czym świadczy choćby to, że wynik ewaluacji nie ma wpływu na wysokość dotacji. Podkreślano, że proces jest oparty na samoewaluacji, tzn. instytucje same przygotowują i składają sprawozdania, co stwarza okazję do takiej prezentacji informacji i danych, by pokazać instytucję od najlepszej strony. Respondenci byli zdania, że może to prowadzić do zniekształcenia wyniku ewaluacji.

Ogólnie dyrektorzy byli zgodni, że ewaluacja oparta na danych ilościowych nie oddaje właściwego obrazu instytucji i uniemożliwia jej sensowną ocenę. Pytani o możliwość stworzenia mechanizmu oceny jakości artystycznej, respondenci wyrażali przekonanie, że stworzenie „obiektywnych, mierzalnych kryteriów” jest „właściwie niemożliwe” ze względu na różnorodną specyfikę instytucji i subiektywny charakter doświadczenia estetycznego. Jeśli jednak ktoś miałby oceniać, powinni to być eksperci, a nie urzędnicy. Zespół ekspercki powinien być zewnętrzny w stosunku do organizatora, choć w jego pracach mógłby uczestniczyć przedstawiciel organizatora. W zespole powinny znaleźć się „miejscowe elity”, a ocena winna uwzględniać specyfikę lokalną, m.in. tradycję, wielkość miasta i uwarunkowania środowiskowe. Ocena powinna wynikać z subiektywnych opinii członków zespołu raczej niż opierać się na z góry określonych kryteriach oceny artystycznej. Niektórzy respondenci uważali, że od ostatecznej oceny powinna zależeć wysokość dotacji.

A jednak pojawiły się również głosy, że zespół ekspercki wcale nie gwarantowałby apolityczności procesu decyzyjnego. Jeden $\mathrm{z}$ respondentów podkreślał, że „w polityce nie ma ciała eksperckiego niezależnego od polityków", a oddanie władzy zespołowi ekspertów jest po prostu inną formą interwencji państwa w działalność artystyczną. 
Oceniać działalność instytucji kultury powinni przede wszystkim odbiorcy ich oferty, uczestnicy zdarzeń programowych. Kompetencje organizatora zwiazane sa raczej z aspektami zarzadczymi i umiejętnym wstuchiwaniem się $w$ opinie krytyków, publiczności, uczestników i ze stałym monitoringiem wszelkiej aktywności programowej.
Nie mitologizujmy ekspertów. Ich zawsze powoluje organizator, oni zawsze sa , skądś”. Żaden ekspert powołany przez urzędnika nie działa w próżni.

\section{Wybór i mianowanie dyrektora teatru}

\section{Organizatorzy teatrów}

Z odpowiedzi respondentów wynika, że konkurs jest dużo częściej stosowaną formą wyboru dyrektora instytucji niż powołanie. Większość respondentów uważa, że powołanie jest skuteczniejszą metodą tylko w niektórych przypadkach, np. gdy wyniki artystyczne i finansowe teatru są dobrze oceniane i umowa $\mathrm{z}$ obecnym dyrektorem zostaje przedłużona lub gdy nie udaje się wyłonić kandydata w wyniku konkursu, bo żaden kandydat nie spełnia założonych kryteriów.

Mimo to respondenci zauważają wady procedury konkursowej:

Samorząd województwa Y obsadza stanowiska dyrektorów $w$ drodze konkursów. Pomimo całej złożoności tej procedury i obarczenia jej możliwościa błędu uznano ten sposób powolywania dyrektorów za najlepszy, najbardziej transparentny. Warto podkreślić jednak, że na skutek nadużyć z wielu stron formuła ta powoli się wyczerpuje. Już od dhuższego czasu problemem byto to, że nie wszyscy wartościowi kandydaci decydowali się na udziat w konkursie. Prawdopodobnie ta tendencja może się pogtębiać.

Niestety, praktyka konkursowa w przypadku teatrów nie przyniosta dobrych rezultatów, np. do konkursu na kandydata na dyrektora Teatru $Z$ zgtosito się 19 osób i po dwudniowych przestuchaniach komisja postanowila nie rekomendować żadnej osoby. Często do konkursów nie zgłaszaja się dobrzy kandydaci $i$ wtaściwie nie ma tu chyba jednoznacznie dobrej metody wyboru, decyzja za kazdym razem podejmowana jest odrębnie i jest obarczona ryzykiem.

\section{Dyrektorzy teatrów}

Respondenci generalnie byli zdania, że procedura konkursowa jest bardziej transparentną metodą wyłonienia dyrektora instytucji artystycznej niż powołanie. Jednocześnie ocena tej procedury nie była jednoznacznie pozytywna. Respondenci zwracali uwagę, że powierzenie wytypowania kandydata gronu eksperckiemu nie chroni teatrów przed ciemną stroną interwencjonizmu władzy. Zwracano uwagę na przypadki przekroczenia przez organizatora jego kompetencji, np. gdy organizator zdecydował o niemianowaniu dyrektora wyłonionego w ramach konkursu. Problemem, według niektórych dyrektorów, jest nieprecyzyjność przepisów. Przykładowo, w Ustawie o organizowaniu i prowadzeniu działalności kulturalnej obowiązek respektowania wyników konkursu przez organizatora nie jest wyrażony explicite. Dlatego wiele w relacjach teatrów i ich organizatorów zależy od niepisanych zasad i dobrych praktyk $^{30}$, które powinno się upowszechniać.

${ }^{30}$ W wyniku prac Grupy Roboczej (patrz przypis 28) powstał Katalog Dobrych Praktyk dokument opisujący rekomendowane przez środowisko teatralne praktyki i procedury wyłaniania dyrektorów teatrów publicznych. 


\section{Generalna ocena relacji teatr - organizator}

\section{Organizatorzy teatrów}

Respondenci pozytywnie oceniali relacje $\mathrm{z}$ dyrektorami oraz środowiskiem teatralnym w ciągu ostatnich lat. Żaden $\mathrm{z}$ respondentów nie ocenił tych relacji negatywnie, w jednym przypadku tylko relacje ze środowiskiem określono jako ,zachowawcze". Wskazywano, że dobre stosunki z teatrami wynikają z przyjętej polityki władz, które nie ingerują $\mathrm{w}$ autonomię programową, repertuarową i kadrową, zostawiając swobodę twórczą.

Dyrektorzy to partnerzy $w$ dialogu. Zdecydowanie można stwierdzić, że relacje organizator - teatr sa oparte na dyskusji. Oczywiście, sa pola trudne (glównie finanse, relacje ze zwiazkami zawodowymi), ale nie ma konfliktów. Marszałek jest dobrze zorientowany $w$ sprawach bieżacych kazdej instytucji, kontakty teatrów z Departamentem Kultury sa regularne i pomocne - chyba dla obu stron.
Dyrektorzy teatrów

Generalną ocenę relacji $\mathrm{z}$ organizatorami można określić jako „poprawną”. W opinii respondentów organizatorzy wywiązują się z obowiązku terminowego zapewniania instytucji środków finansowych. Mimo to niektórzy respondenci wyrażali przekonanie, że ich pozycja w tej relacji jest bliższa ,petentowi” niż ,partnerowi” i nie ma wiele wspólnego $\mathrm{z}$ otwartym dialogiem. Pojawiały się opinie, że władze samorządowe nie rozumieją specyfiki instytucji artystycznej.

Relacje między organizatorem i teatrem rzadko bywaja partnerskie. Tam, gdzie jest jeden teatr, stuż on władzom jako miejsce organizacji imprez. Władzom miejskim bardziej zależy na frekwencji niż funkcjach obywatelskich teatru.

\section{b) Relacje teatrów publicznych i ich organizatorów - konflikty i kontrowersje}

Wyniki badania sugerują, że relacje między teatrami i ich organizatorami - choć nierzadko trudne i pełne napięć - pozostawiają instytucji spory zakres autonomii. Rola organizatora polega na kontroli administracyjnej o charakterze rutynowym i doraźnym, niemającym większego wpływu na merytoryczną działalność teatru. Władze nie formułują wobec podległych sobie instytucji konkretnych oczekiwań oraz nie postrzegają ich w kategorii ,instrumentów” do realizacji szerzej zakrojonych planów lub strategii. Dokumenty strategiczne dotyczące kultury - z kilkoma wyjątkami - nie uwzględniają teatrów jako odrębnych bytów, którym przypisane byłyby praktyczne zadania. Wydaje się, że dla większości organizatorów najważniejsze jest przestrzeganie procedur.

Taki obraz, zakładający neutralność władz i autonomię instytucji, może jednak wydawać się sprzeczny z obserwowaną na co dzień rzeczywistością. Ostatnie lata obfitowały w doniesienia prasowe o konfliktach i nieporozumieniach na linii teatr - organizator. Konflikty dotyczyły przede wszystkim dwóch kwestii: wyboru dyrektora oraz kontrowersji związanych z treścią dzieła. Jednym z najgłośniejszych i wzbudzających żywe reakcje środowiska teatralnego był konflikt dotyczący wyboru dyrektora Teatru Polskiego we Wrocławiu (2016 r.). Podkreślano niekompetencję kandydata, zarówno od strony artystycznej, jak i organizacyjnej, ale - co ważniejsze z punktu widzenia niniejszego tekstu - podważano także sam sposób przeprowadzenia konkursu. Choć, jak się wydaje, wszystkie procedury zostały przeprowadzone zgodnie z przepisami, zadecydowały inne czynniki, takie jak sympatie organizatora czy relacje poprzedniego dyrektora z Urzędem Marszałkowskim i Ministerstwem Kultury i Dziedzictwa Narodowego. Okazało się, że konkurs, uważany powszechnie za 
najbardziej ,transparentną" z dostępnych metod wyboru dyrektora, nie chroni przed niechcianym politycznym wpływem i zakulisowymi układami, a może nawet stanowi „maskę” dla interwencji władzy (by użyć sformułowania R. B.-M. Quinn) w postaci rzekomo demokratycznych procedur.

Konflikty i kontrowersje związane z treścią dzieła są również istotne dla kwestii autonomii instytucji. Zwykle polegają one na artykułowaniu przez przedstawicieli władzy zarzutów dotyczących ideologicznej warstwy spektaklu lub jego elementów. Czasem obiekcjom tym towarzyszą groźby natury ekonomicznej (obniżenie lub cofnięcie dotacji). Wydaje się jednak, że do tej pory groźby te rzadko były realizowane, a ich cel stanowiło raczej zyskanie przez władze sympatii pewnych środowisk (np. prawicowych lub religijnych) oraz potencjalnego elektoratu niż przejęcie realnej kontroli nad funkcjonowaniem instytucji.

Wbrew wcześniejszej intuicji można więc założyć, że obraz wyłaniający się z badania oraz wspomniane konflikty nie są sprzeczne, ale się dopełniają. Napięcia i nieporozumienia są incydentami na tle jednostajnej, biurokratycznej codzienności. Być może mamy do czynienia z relacją przyczynowo-skutkową: niechęć do formułowania jasnych kryteriów oceny lub podziału zadań daje okazję do nadużyć tak samo, jak nieprecyzyjne zasady wyboru ekspertów w systemie arm's length. Nasuwa się jeden wniosek: trudno o niezawodny, tzn. chroniący przed interwencją władz, system zarządzania kulturą, gdy w grę wchodzą środki publiczne.

\section{Podsumowanie}

Celem tego artykułu było omówienie dwóch modeli polityki kulturalnej w kontekście autonomii instytucji. Główna teza zakładała, że twierdzenia o rzekomej autonomiczności instytucji artystycznych w systemie arm's length są ugruntowane na teoretycznych przesłankach raczej niż praktyce i doświadczeniu. Zadaniem tego tekstu nie była jednak deprecjacja zasady przedłużonego ramienia, tylko próba krytycznej analizy typologii Hillmana-Chartranda i McCaughey. Zaprezentowana w artykule literaturowa i badania empiryczne pozwalają stwierdzić, że zarówno model Architekta, jak i Patrona zawiera spory potencjał wpływu polityki na funkcjonowanie instytucji. Potencjał ten w obu modelach występuje na różnych poziomach i etapach. W modelu Architekta władze publiczne odgrywają istotną rolę na etapie wyboru zarządzającego instytucją. W Polsce rola ta może być decydująca zarówno w przypadku powołania, jak i konkursu - organizator przez umiejętne formułowanie wymagań konkursowych może utorować drogę preferowanym przez siebie kandydatom.

Przedstawiciele władzy publicznej stanowią ponadto większość składu komisji konkursowej (pięciu spośród dziewięciu członków). W modelu Patrona władza wpływa na funkcjonowanie instytucji poprzez mechanizm jej rozliczania, za pomocą szczegółowych wskaźników, celów i kryteriów (zob. s. 5-6). Nakładając na instytucję obowiązek realizacji tych celów, państwo w znaczący sposób wpływa na jej działalność. 


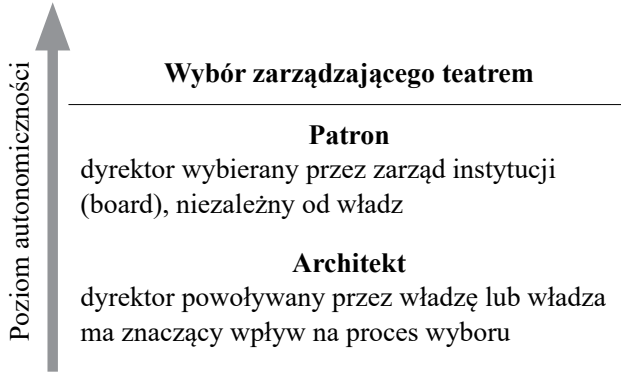

System ewaluacji teatrów

\section{Architekt}

ewaluacja rutynowa, skoncentrowana na przestrzeganiu procedur administracyjnych

\section{Patron}

ewaluacja na podstawie szczegółowych kryteriów definiowanych przez władzę

\section{1. Poziom autonomiczności teatrów w modelu Patrona i Architekta}

Źródło: Opracowanie własne

Rysunek 1 pokazuje, jak powyższe relacje wpływają na poziom autonomiczności teatrów w modelu Patrona i Architekta. Chociaż schemat jest uproszczeniem i pomija istotne niuanse (np. w modelu Architekta konkurs może być metodą wyboru niezależnego, popieranego przez artystów kandydata na dyrektora), to jednak na poziomie ogólnym dostrzegalne są główne pola możliwych napięć między teatrami a władzą.

Wnioski, które płyną z powyższych analiz, mogą być instruktywne dla polskiego systemu administrowania teatrami. Warto się nad nimi zastanowić, zwłaszcza że jedna z poważniejszych propozycji reform kultury polskiej po roku 1989 uwzględniała adaptację zasady arm 's length ${ }^{31}$. Tymczasem doświadczenia krajów, które wdrożyły system ekspercki, pozwala dostrzec kruchość tego rozwiązania. W krajach skandynawskich czy bałtyckich rady sztuki albo nigdy nie uzyskały pełnej samodzielności, albo szybko ją utraciły. W Szwecji założona w roku 1994 Fundacja Kultury Przyszłości (Stiftelsen framtidens kultur) odgrywała rolę niezależnego pośrednika do chwili przejęcia władzy przez partię socjaldemokratyczną; odtąd kultura miała realizować zadania społeczne, wpisujące się w oficjalną agendę polityczną. Nowy rząd przejął sporą część kontroli nad fundacją, która do dziś balansuje między zależnością od władz centralnych a autonomią ${ }^{32}$. Podobny los spotkał katalońską Radę Sztuki (tzw. ConCa-Consell nacional de la Cultura $i$ de les arts), która po dwóch latach od powstania (w 2009 roku) została pozbawiona przez rząd Katalonii swoich uprawnień i stała się ciałem doradczym. Z kolei w krajach bałtyckich utworzone w latach dziewięćdziesiątych XX wieku narodowe rady sztuki, choć mają spore kompetencje (np. na Litwie jedynie osiem narodowych instytucji otrzymuje finansowanie bezpośrednio z budżetu państwa), nigdy nie wydostały się spod kontroli postsowieckich

${ }^{31}$ Mowa o propozycji reformy kultury autorstwa Wojciecha Misiąga, zakładającej stworzenie polskiej Rady Sztuki. Zob. D. Ilczuk, W. Misiąg, Finansowanie i organizacja kultury w gospodarce rynkowej, Warszawa 2003.

${ }_{32}$ M.N. Predelli, B. Baklien, Autonomy and dependence in state cultural policy: a case study of the foundation culture of the future in Sweden, „International Journal of Cultural Policy” 2003, nr 9 (3), s. 299-317. 
związków zawodowych twórców ${ }^{33}$. Według charakterystyki zasady arm s length Pera Mangseta $^{34}$, związki zawodowe artystów nie powinny mieć wpływu na decyzje Rady Sztuki, gdyż prowadziłoby to do jej upolitycznienia ${ }^{35}$. Praktyka funkcjonowania systemu arm's length pokazuje jednak, że wraz z postępującą od lat siedemdziesiątych „demokratyzacją w kulturze”, rady sztuki nie podejmują już decyzji wyłącznie na podstawie subiektywnych ocen jej członków, ale muszą uwzględniać stanowiska oraz interesy różnych aktorów społecznych działających w dziedzinie kultury ${ }^{36}$.

W Polsce model Patrona może być szczególnie ceniony za sposób powoływania dyrektorów teatrów, których wybiera niezależny zarząd dyrektorów instytucji (board of directors) lub rada powiernicza (board of trustees). Trzeba jednak zwrócić uwagę, że rozwiązanie to wynika $\mathrm{z}$ autonomicznego statusu tych organizacji. W Holandii powoływanie dyrektora przez zarząd stało się możliwe po autonomizacji instytucji publicznych, tzn. ich transformacji w organizacje non-profit ${ }^{37}$. W Wielkiej Brytanii autonomia teatrów ma wyraźne konsekwencje finansowe - z raportu Stephena Hetheringtona ${ }^{38}$ o finansowaniu teatrów brytyjskich wynika, że dotacje publiczne Royal National Theatre czy Royal Opera House nie przekraczają 30\% ich przychodów. O tym, jak słodko-gorzki może być smak wolności, przekonują się instytucje w Pradze, gdzie od roku 2002 trwa mozolny proces autonomizacji teatrów publicznych ${ }^{39}$. Warto o tym pamiętać w kontekście roszczeń polskich instytucji artystycznych do autonomiczności. Jak pisał Dragan Klaić:

Zapewnienie autonomii instytucji i jej procesu twórczego, a zarazem jej zgodności z interesem publicznym, który reprezentuje zarząd, wymaga subtelnego balansowania. Autonomia nie jest jej z góry dana, nie należy jej mylić z zupełną niezawisłością. Jest to raczej zespół stosunków - dynamicznych i zmiennych, nieustannie negocjowanych, potwierdzanych i bronionych, uwzględniających różne wzajemne zależności $[\ldots]^{40}$.

${ }^{33}$ E. Rindzevičiūte, Post-Soviet transformation of Lithuanian state cultural policy: the meanings of democratisation, „International Journal of Cultural Policy” 2012, nr 18 (5), s. 563-578.

${ }^{34}$ P. Mangset, dz. cyt., s. 283.

${ }^{35}$ Postulat ten jest ciekawy z punktu widzenia Polski, gdzie to właśnie przedstawiciele związków lub stowarzyszeń zawodowych są uznawani za „,niezależny” głos na rzecz artystów i wolności sztuki (np. w konkursach dyrektorskich).

${ }^{36} \mathrm{~K}$. Lewandowska, Using Isaiah Berlin's two concepts of liberty to rethink cultural policy: a case of Poland, ,International Journal of Cultural Policy”2016, w druku, DOI: 10.1080/10286632.2016.1156101.

37 S. Engelsman, Privatization of Museums in the Netherlands: twelve years later, „Museum International" 2006, nr 58 (4), s. 37-43.

${ }^{38}$ S. Hetherington, The Interdependence of Public and Private Finance in British Theatre, Manchester 2016.

${ }^{39}$ K. Vojtíšková, R. Lorencová, Public funding of culture in the Czech Republic since the fall of the iron curtain: contemporary dilemmas, ,International Journal of Cultural Policy” 2015, $\mathrm{nr} 21$ (5), s. 529-553.

${ }^{40}$ D. Klaić, Gra w nowych dekoracjach. Teatr publiczny pomiędzy rynkiem a demokracja, Warszawa 2014. 


\section{Bibliografia}

Belfiore E., Auditing culture: the subsidised cultural sector in the New Public Management, „International Journal of Cultural Policy" 2004, nr 10 (2), s. 183-202.

Blomgren R., Autonomy or democratic cultural policy: that is the question, „International Journal of Cultural Policy" 2012, nr 18 (5), s. 519-529.

Burnham P., New Labour and the politics of depoliticisation, „British Journal of Politics and International Relations" 2001, nr 3 (2), s. 127-149.

Cummings M., Katz R., Government and the arts: an overview [w:] M. Cummings, R. Katz (red.), The patron state: government and the arts in Europe, North America and Japan, New YorkOxford 1987, s. 3-16.

Department for Culture, Media and Sport, Charitable Giving Indicators Publication 2014/2015, 2015, https://www.gov.uk/government/statistics/charitable-giving-indicators-201415 [odczyt: 15.02.2017].

Engelsman S., Privatization of Museums in the Netherlands: twelve years later, „Museum International" 2006, nr 58 (4), s. 37-43.

Hausner J., Malczyk K., Maźnica Ł. Strycharz J., Diagnoza potencjału podmiotów kultury w zakresie realizacji Programu Rozwoju Kultury 2020: analiza sytuacji zastanej, Kraków 2016.

Hetherington S., Arm 's-length funding of the arts as an expression of laissez-faire, „International Journal of Cultural Policy" 2015, nr 23 (4) s. 482-494.

Hetherington S., The Interdependence of Public and Private Finance in British Theatre, Manchester 2016.

Hillman-Chartrand H., McCaughey C., The arm's length principle and the arts: an international perspective - past, present and future [w:] M. Cummings, J.M.D. Schuster (red.), Who's to pay for the arts? The international search for models of support, New York 1989, s. 43-73.

Hołda J., Komentarz do ustawy o organizowaniu i prowadzeniu działalności kulturalnej, Warszawa 2012.

Ilczuk D., Misiąg W., Finansowanie i organizacja kultury w gospodarce rynkowej, Warszawa 2003. Inkei P., Arm's Length Financing in Culture: Why? Why Not?, Budapeszt 2001, http://www.budobs. org/grant-paper-dec.htm [odczyt: 13.02.2015].

Inkei P., 2002, Why Not Indeed?, Budapeszt 2002, http://www.budobs.org/grant- paper02.htm [odczyt: 3.03.2015].

Klaić D., Gra w nowych dekoracjach. Teatr publiczny pomiędzy rynkiem a demokracja, Warszawa 2014.

Lewandowska K., Using Isaiah Berlin's two concepts of liberty to rethink cultural policy: a case of Poland, „International Journal of Cultural Policy” 2016, w druku, DOI: 10.1080/10286632.2016.1156101.

Loosely D., Cultural policy in France since 1959: arm's length, or 'up close and personal?', Kopenhaga 2001.

Madden C., The independence of government arts funding: a review, „D'Art Topics in Art Policy" 2009 , nr 9.

Mangset P., The arm's length principle and the art funding system: comparative approach [w:] M. Pyykkönen, N. Simanainen, S. Sokka (red.), What about cultural policy? Interdisciplinary perspectives on culture and politics, Jyväskylä 2009, s. 273-298.

March J.G., Olsen J.P., Instytucje. Organizacyjne podstawy polityki, Warszawa 2005.

Ploeg van der F., The Making of Cultural Policy: a European Perspective, Working Paper no. 1524, Monachium 2005.

Predelli M.N., Baklien B., Autonomy and dependence in state cultural policy: a case study of the foundation culture of the future in Sweden, ,International Journal of Cultural Policy” 2003, nr 9 (3), s. 299-317. 
Quinn R.-B.M., Distance or intimacy? The arm's length principle, the British government and the arts council of Great Britain, „International Journal of Cultural Policy” 1997, nr 4 (1), s. 127 159.

Rindzevičiūte E., Post-Soviet transformation of Lithuanian state cultural policy: the meanings of democratisation, „International Journal of Cultural Policy” 2012, nr 18 (5), s. 563-578.

Tomczyk E., Instytucja kultury nie jest formalnie podporzadkowana swojemu organizatorowi, 2012, http://www.samorzad.lex.pl/czytaj/-/artykul/instytucja-kultury-nie-jest-formalnie-podporzadkowana-swojemu-organizatorowi/ [odczyt: 13.03.2017].

Ulldemolins J.R., Arostegui A.R., The governance of national cultural organisations: comparative study of performance contracts with the main cultural organisations in England, France and Catalonia (Spain), „International Journal of Cultural Policy” 2013, 19 (2), s. 249-269.

Upchurch A.R., Keynes's legacy: an intellectual's influence reflected in arts policy, „International Journal of Cultural Policy" 2011, nr 17 (1), s. 69-80.

Vojtíšková K., Lorencová R., Public funding of culture in the Czech Republic since the fall of the iron curtain: contemporary dilemmas, „International Journal of Cultural Policy” 2015, nr 21 (5), s. 529-553. 